\title{
O uso de objetos de aprendizagem para o ensino de espanhol como língua estrangeira: análise e propostas didáticas
}

\author{
El uso de objetos de aprendizaje para la enseñanza de \\ español como lengua extranjera: análisis y propuestas \\ didácticas
}

\begin{abstract}
The use of learning objects for teaching Spanish as a foreign language: analysis and didactic proposals ${ }^{1}$
\end{abstract}

\author{
Raquel Bicalho de Carvalho Barrios* \\ Vanessa Cruz Mantoani**
}

\begin{abstract}
RESUMO: Os recursos tecnológicos estão cada vez mais imersos em nosso cotidiano. São utilizados de diversos modos e com variadas finalidades: comunicação, entretenimento, organização/planejamento, entre outras. Diante desse contexto, seu fim educativo também se tornou uma necessidade e instituições escolares e professores passaram a buscar formas de incluir essas ferramentas em sala de aula visando acompanhar e atender as demandas de uma sociedade tecnológica. Desse modo, este artigo tem como objetivo geral estabelecer um breve panorama histórico do uso de tecnologia no ensino de línguas e incentivar a sua utilização em aulas de espanhol como língua estrangeira (ELE) para aprendizes brasileiros. Para tanto, e de modo mais específico, temos por objetivo analisar dois OA (áudio e vídeo) produzidos para o ensino-aprendizagem de ELE disponibilizados no Banco Internacional de Objetos Educacionais (BIOE) e propor atividades a partir desses dois OA analisados. Utilizamos como referencial teórico, autores que discorrem sobre terminologias relacionadas à tecnologia (LÉVY, 1999; PAIVA, 2015; PRENSKY, 2001, 2010); recursos tecnológicos e ensino (ARAÚJO, 2013; PRENSKY, 2001, 2010; SILVA, 2013; TALLEI e COELHO, 2012) e objetos educacionais (ARAÚJO, 2013; WILEY, 2000).
\end{abstract}

\footnotetext{
${ }^{1}$ A ideia deste trabalho surgiu a partir de uma proposta avaliativa sugerida na disciplina "Novas Tecnologias, Linguagem e Escola", ministrada pela Profa. Dra. Eliana Maria Severino Donaio Ruiz, no Programa de Pós-Graduação em Estudos da Linguagem da Universidade Estadual de Londrina, e cursada pelas autoras.
}

*Mestra em Estudos da Linguagem pelo PPGEL-UEL - Programa de Pós-Graduação em Estudos da Linguagem da Universidade Estadual de Londrina. Professora colaboradora da Universidade Estadual do Paraná (UNESPAR, campus Apucarana). raquelbicalho@hotmail.com

**Mestra em Estudos da Linguagem pelo PPGEL-UEL - Programa de Pós-Graduação em Estudos da Linguagem da Universidade Estadual de Londrina. Professora colaboradora da Universidade Estadual do Paraná (UNESPAR, campus Apucarana). vcmantoani@yahoo.com.br 
PALAVRAS-CHAVE: Objetos de Aprendizagem. Uso de tecnologias. Propostas didáticas. Ensino de Língua Espanhola.

RESUMEN: Los recursos tecnológicos están cada vez más inmersos en nuestro cotidiano. Son utilizados de diversos modos y con varias finalidades: comunicación, entretenimiento, organización/planeamiento, entre otras. Ante ese contexto, su fin educacional también se volvió una necesidad e instituciones escolares y profesores pasaron a buscar formas de incluir esas herramientas en sala de clase con el fin de acompañar y atender las demandas de una sociedad tecnológica. De ese modo, este artículo tiene como objetivo general establecer un breve panorama histórico del uso de la tecnología en la enseñanza de lenguas e incentivar su utilización en clases de español como lengua extranjera (ELE) para aprendices brasileños. Para tanto, y de modo más específico, tenemos por objetivo analizar dos OA (audio y video) producidos para la enseñanza y aprendizaje de ELE disponibles en el Banco Internacional de Objetos Educacionales (BIOE) y proponer actividades a partir de esos dos OA analizados. Utilizamos como referencial teórico, autores que versan sobre terminologías relacionadas con la tecnología (LÉVY, 1999; PAIVA, 2015; PRENSKY, 2001, 2010); recursos tecnológicos y enseñanza (ARAÚJO, 2013; PRENSKY, 2001, 2010; SILVA, 2013; TALLEI e COELHO, 2012) y objetos educacionales (ARAÚJO, 2013; WILEY, 2000).

PALABRAS ClAVE: Objetos de Aprendizaje. Uso de tecnologías. Propuestas didácticas. Enseñanza de Lengua Española.

ABSTRACT: Technological resources are more and more immersed in our daily lives. They are used in several ways and with varied purposes: communication, entertainment, organization/planning, among others. Given this context, its educational purpose also became a necessity and school institution and teachers have started to seek ways to include these tools in the classroom in order to follow and meet the demands of a technological society. Thus, this article aims to establish a brief historical overview of the use of technology in language teaching and to encourage its use in Spanish as a foreign language (ELE) classes for Brazilian learners. To do so, and more specifically, we aim to analyze two OA (audio and video) produced for the teachinglearning of ELE available in the International Bank of Educational Objects (BIOE) and propose activities from these two $\mathrm{OA}$ analyzed. We use as theoretical reference, authors that talk about terminologies related to technology (LÉVY, 1999; PAIVA, 2015; PRENSKY, 2001, 2010); technological resources and teaching (ARAÚJO, 2013; PRENSKY, 2001, 2010; SILVA, 2013; TALLEI e COELHO, 2012) and educational objects (ARAÚJO, 2013; WILEY, 2000).

KEYWORDS: Educational Objects. Use of technology. Teaching proposal. Teaching Spanish.

\section{Introdução}

O ensino, seja de uma língua estrangeira ou não, está em constante discussão e modificação. Métodos, abordagens, recursos didático/pedagógicos 
e outros aspectos são frequentemente debatidos com o intuito de aperfeiçoar e atualizar a prática docente.

Nesse contexto, o uso das tecnologias digitais da informação e comunicação (TDIC) tem sido, atualmente, um dos assuntos abordados e analisados pelos profissionais da educação. $O$ grande avanço dessas ferramentas e o amplo acesso a elas, configuram-se como um dos motivos para que a utilização desses recursos como instrumentos de ensino-aprendizagem torne-se alvo de reflexão e discussão.

No entanto, ainda que alunos e professores, de forma geral, usem a tecnologia em seu cotidiano, o momento de levá-la para a sala de aula ainda é um pouco complicado e requer alguns cuidados.

Assim como qualquer outra proposta didática, as que têm como foco o uso de recursos tecnológicos precisam ter objetivos previamente definidos e não devem ser usadas somente como pretexto para divertir/distrair os alunos ou para levar a eles algo "diferente". Também há que atentar-se para o desenvolvimento de atividades que realmente explorem as funções da tecnologia e não sejam somente uma transposição daquilo que já era feito sem ela.

Diante do exposto, como objetivo geral deste artigo, visamos estabelecer um breve panorama histórico do uso de tecnologia no ensino de línguas e incentivar o uso da tecnologia em aulas de espanhol como língua estrangeira (ELE) para aprendizes brasileiros. Para tanto, e de modo mais específico, temos por objetivo analisar dois OA produzidos para o ensino-aprendizagem de ELE disponibilizados no Banco Internacional de Objetos Educacionais (BIOE) e propor atividades a partir dos dois OA analisados.

Tendo em vista que esses recursos podem ser produzidos, publicados e acessados no BIOE e, consequentemente, utilizados por profissionais da educação em sala de aula, acreditamos na relevância de analisá-los e de sugerir possíveis caminhos para o seu uso em uma aula de língua espanhola. Desse modo, nosso trabalho contribuirá com a prática docente, visto que apresenta propostas de atividades e promoverá uma maior reflexão sobre o uso das 
tecnologias em nosso contexto educacional, estimulando a utilização dessas ferramentas.

Como fundamentação teórica, utilizamos estudiosos que tratam sobre os aspectos determinados a seguir:

- Tecnologia e ensino: Prensky (2001, 2010); Tallei e Coelho (2012); Araújo (2013); Silva (2013);

- Histórico da tecnologia: Paiva (2015);

- Terminologias sobre o tema discutido: Lévy (1999); Prensky (2001, 2010);

- Objetos educacionais: Wiley (2000); Araújo (2013);

- O uso de áudios no ensino de línguas: Tallei (2012);

- O uso do vídeo no ensino de línguas: Fernández et.al(2010); Moran (1995);

Em um primeiro momento, discorremos sobre o uso da tecnologia no ensino de língua e o atual perfil dos alunos, estabelecendo um breve panorama histórico a respeito do tema. Em seguida, tratamos dos conceitos de objetos de aprendizagem e apresentamos algumas informações sobre o Banco Internacional de Objetos Educacionais e, por fim, analisamos dois exemplares destes objetos e sugerimos duas propostas didáticas com o seu uso.

Gostaríamos de aclarar que nesta pesquisa utilizamos os termos "objetos de aprendizagem" (OA) e objetos educacionais (OE) como sinônimos e que escolhemos recursos em formato de áudio e de vídeo para as sugestões de atividades.

\section{Tecnologia e ensino de línguas}

Nas últimas décadas, grande discussão em torno das tecnologias vem ganhando espaço na área de Letras por tratar de uma temática cada vez mais presente na sociedade. Partindo do pressuposto de que as salas de aulas devem estar atentas às demandas da sociedade como um todo, entendemos que o uso de aparatos tecnológicos aumentará no decorrer dos anos. Desse 
modo, o processo de ensino-aprendizagem de línguas não pode excluí-los de suas aulas, visto que "el escenario vigente presenta la necesidad de evaluar los nuevos desafíos que enfrenta el profesor y que conlleva a éste a adaptarse a las demandas que proponen estos medios" (TALLEI; COELHO, 2012, p. 14)2.

Por esse motivo, nas aulas de língua estrangeira, especificamente de língua espanhola, contexto de nosso estudo, as TDIC têm muito a contribuir pelo fato de poderem proporcionar conteúdo crítico, além de ser um recurso didático motivador.

Considerando que o uso de tecnologias no ensino de línguas ocorre há anos, apresentamos um breve panorama histórico sobre ele.

\section{Panorama histórico}

Com o objetivo de compreendermos melhor a tecnologia e sua relação com o processo de ensino-aprendizagem, consideramos necessário recordar seu desenvolvimento.

Primeiramente, não podemos esquecer a escrita como recurso tecnológico, visto que os livros didáticos são uma evolução dos papiros e continuam sendo utilizados nos dias de hoje, ainda que existam tablets e ebooks. De acordo com Paiva (2015, p. 02), "a invenção da imprensa por Gutemberg em 1442 foi a primeira grande revolução tecnológica na história da cultura humana, mas a socialização do livro não foi um processo tranquilo", pois, segundo a autora, o livro e o computador passaram pelos mesmos problemas de introdução em nossa sociedade.

Entretanto, com a evolução tecnológica, o áudio e o vídeo foram introduzidos no ambiente escolar e o ensino de língua estrangeira teve como foco a oralidade, ainda que utilizasse uma metodologia com ênfase na repetição e imitação de frases gravadas que, consequentemente, dariam lugar aos gravadores de fita magnética e aos laboratórios de línguas, nos quais os alunos

2 O cenário vigente apresenta a necessidade de avaliar os novos desafios que o professor enfrenta e que o levam a se adaptar às demandas que propõem estes meios (Tradução nossa). 
podiam gravar e ouvir suas falas no idioma estudado. Algumas metodologias de ensino, como o método Audiovisual, utilizaram dessa tecnologia para ensinar a aprendizes de línguas. Nesse caso, a televisão ganhou destaque e contribuía para a visualização de vídeos e imagens acompanhadas de falas de naturais de determinado idioma.

Com o decorrer dos anos,

A cada nova tecnologia, a escola, especialmente no ensino de línguas, busca inserir essa nova ferramenta nas práticas pedagógicas em uma tentativa de melhorar a mediação entre o aprendiz e a língua estrangeira. Assim, o livro ganhou a companhia do som e da imagem, oferecendo input menos artificial (PAIVA, 2015, p. 07).

Outro aparato tecnológico que muito contribui para 0 ensinoaprendizagem é o computador, que pode auxiliar com diversos recursos como jogos, ferramentas de escrita e, principalmente, a Internet.

Nesse ambiente, o indivíduo não somente pode exercer funções individualizadas como, por exemplo, realizar buscas em sites de pesquisas e consultas a e-mails, mas, também, pode interagir com pessoas do mundo todo por meio de salas de bate-papo e redes sociais como Facebook, Twitter e Skype. Atualmente, a Internet vai mais adiante no ensino-aprendizagem e propicia aos interessados aulas virtuais com o Ensino a Distância (EaD). Muitas universidades em todo o território nacional oferecem cursos online aos alunos e inclusive em cursos presenciais o ensino também pode ser desenvolvido em um ambiente virtual como reforço, como é o caso da Plataforma Moodle, muito utilizada em disciplinas em que o aprendiz pode interagir com seu professor e colegas por meio de realização de tarefas e fóruns de discussão, além de outras ferramentas disponíveis.

Contudo, torna-se necessário compreender alguns dos aspectos que se relacionam com o uso da tecnologia e, para tanto, apresentamos, a seguir, conceitos com base em estudiosos da área. 


\section{Terminologias}

Conforme Lévy (1999, p. 167), ciberespaço, é o "novo meio de comunicação que surge com a interconexão mundial de computadores", é o ambiente no qual ocorre a comunicação entre pessoas de todo o mundo. Desse modo, para o autor, o ciberespaço é também um espaço no qual há um mercado de informações e de conhecimento. É nesse meio que podemos encontrar a cibercultura, "conjunto de técnicas materiais e intelectuais, de práticas, de atitudes, de modos de pensamento e de valores, que se desenvolvem juntamente com o crescimento do ciberespaço" (LÉVY, 1999, p. 17).

Se um dos focos do ensino-aprendizagem de língua estrangeira é a comunicação, o ciberespaço e a cibercultura a permitem de forma ampla, pois existe a possibilidade de nos comunicarmos com qualquer indivíduo por meio da tecnologia. Nessa relação entre a tecnologia e a cultura, podemos compartilhar informações e conhecimentos e, é nesse sentido, que as TDIC contribuem com a educação. Os professores podem utilizar das ferramentas presentes na Internet com o intuito de possibilitar a comunicação de seus estudantes com a língua estrangeira e a cibercultura e promover um debate reflexivo, contribuindo com a formação crítica dos alunos.

Entretanto, é fundamental entendermos quem são os nossos alunos para podermos proporcionar atividades que contemplem suas necessidades. De acordo com Prensky (2001, p.1),

Os alunos de hoje - do maternal à faculdade - representam as primeiras gerações que cresceram com esta nova tecnologia. Eles passaram a vida inteira cercados e usando computadores, vídeo games, tocadores de música digitais, câmeras de vídeo, telefones celulares, e todos os outros brinquedos e ferramentas da era digital. [...] Os jogos de computadores, e-mail, a Internet, os telefones celulares e as mensagens instantâneas são partes integrais de suas vidas. 
Assim sendo, para o autor, a tecnologia e especificamente a Internet fazem parte de suas vidas e, portanto, os estudantes são denominados por Prensky (2001) de nativos digitais por estarem em constante contato e saberem como lidar com tais ferramentas, visto que muitos nasceram e cresceram numa era tecnológica.

A esse respeito, entendemos que propor atividades para apoio da prática docente é fundamental, pois,

\begin{abstract}
Estas nuevas maneras de producir, conjuntamente con las nuevas prácticas discursivas que están surgiendo en la era digital, exigen el desarrollo de las competencias de lectura y de escritura en estos nuevos medios. Para que dicho proceso resulte efectivo es necesario que se tenga el dominio de los varios formatos y soportes que están presentes en las escuelas y también fuera de ellas, ya que la sociedad $y$ el mercado profesional exigen el conocimiento y una competencia digital cada vez mas creciente. Por eso, tenemos en cuenta la necesidad de la actualización y capacitación de los profesores y, además, algunos cambios en las instituciones (TALLEI; COELHO, 2012 , p. 16) ${ }^{3}$.
\end{abstract}

Acreditamos que apresentar propostas didáticas para o ensino e aprendizagem de ELE possa auxiliar professores em sua prática, visto que dúvidas surgem quando se trata do uso das TDIC no ensino de línguas. Para tanto, torna-se essencial compreender um pouco mais sobre nosso objeto de estudo: os objetos de aprendizagem, descritos na seção seguinte.

\title{
Os objetos de aprendizagem (OA) e o Banco Internacional de Objetos Educacionais (BIOE)
}

Nesta seção dissertaremos sobre os objetos de aprendizagem, com base nas reflexões teóricas de Araújo (2013). A autora, em seu artigo "A avaliação

\footnotetext{
${ }^{3}$ Estes novos modos de produzir, juntamente com as novas práticas discursivas que estão surgindo na era digital, exigem o desenvolvimento das competências de leitura e escrita nestes novos meios. Para que tal processo se efetive é necessário que se tenha o domínio dos vários formatos e suportes que estão presentes nas escolas e também fora delas, já que a sociedade e o mercado profissional exigem o conhecimento e uma competência digital cada vez mais crescente. Por isso, consideramos a necessidade da atualização e capacitação dos professores e, além disso, algumas mudanças nas instituições. (Tradução nossa).
} 
de objetos de aprendizagem para o ensino de língua portuguesa: análise de aspectos tecnológicos ou didático-pedagógicos?" apresenta definições dessas ferramentas, discorre sobre suas características e, por fim, analisa alguns exemplos disponíveis no BIOE que têm como foco o ensino de língua portuguesa.

Ainda que neste trabalho nossa proposta seja voltada ao ensino de língua estrangeira e não de português, escolhemos utilizar esse referencial teórico, pois acreditamos que a pesquisadora em questão aborda o tema de forma clara, objetiva e reflexiva e expõe conceitos relevantes para a nossa pesquisa.

Em um primeiro momento, Araújo (2013) argumenta que o surgimento dos objetos de aprendizagem se deu em razão da necessidade de criação de novas estratégias de ensino-aprendizagem para a web e da economia de profissionais e de tempo na elaboração desses materiais. Ela ainda aponta que, apesar de a discussão sobre estes recursos ocorrerem desde meados da década de 90, ainda não há um consenso sobre a definição para estes elementos.

Nesse sentido, a autora se vale de algumas definições apontadas por Wiley (2000) na tentativa de destrinchar as características dessas entidades digitais. Entre os conceitos apresentados, elencamos alguns a seguir:

- "uma entidade, digital ou não digital, que pode ser usada, reusada ou referenciada durante o ensino com suporte tecnológico" (LOM, 2000 apud WILEY 2000, p.5).

- "qualquer coisa" (DOWNES, 2003; FRIESEN, 2001; MORTIMER, 2002 apud LEFFA, 2006, p.6) Neste caso, o uso que se faz do objeto o tornaria ou não um OA.

- "qualquer coisa digital" (WILEY, 2000).

- "qualquer coisa com objetivo educacional" (QUINN; HOBBS, 2000; DOORTEN et al., 2004 apud LEFFA, 2006, p.6).

- "qualquer coisa digital com objetivo educacional" (ALBERTA LEARNING, 2002; CISCO SYSTEMS, 2001; KOPER, 2001). 
Assim como Araújo (2013), utilizamos como embasamento para nossa investigação a última definição apresentada, ou seja, consideramos que um vídeo, uma animação, um áudio, um jogo eletrônico ou qualquer outro recurso digital que tenha sido elaborado com fins didáticos são OE.

A partir da análise desses exemplos de definições compilados pela autora, podemos observar que realmente não há um consenso sobre o conceito em pauta e que ele pode ser bastante amplo. No entanto, há alguns aspectos que, pautados em parâmetros internacionais, são admitidos como padrões inerentes a qualquer $\mathrm{OA}$. Eles são enumerados pela pesquisadora da seguinte forma:

1. Reusabilidade: ser reutilizado diversas vezes em diversas situações e ambientes de aprendizagem;

2. Adaptabilidade: ser adaptável a diversas situações de ensino e aprendizagem;

3. Granularidade: apresentar conteúdo atômico, para facilitar a reusabilidade;

4. Acessibilidade: ser facilmente acessível via Internet para ser usado em diversos locais ou, ainda, ser potencialmente acessível a usuários com necessidades especiais;

5. Durabilidade: apresentar possibilidade de continuar a ser usado independente da mudança de tecnologia;

6. Interoperabilidade: apresentar possibilidade de operar através de variedades de hardwares, sistemas operacionais e browsers (ARAÚJO, 2013, p.186).

Diante destes aspectos, observamos que as características necessárias para que algo seja considerado um objeto educacional são bastante rigorosas. Desenvolver uma ferramenta que possa ser reusável e adaptável a diversas situações e, principalmente, que possa continuar sendo utilizada ainda que haja uma mudança de tecnologia pode ser muito difícil e trabalhoso.

Araújo (2013) defende que, entre os traços apontados, a granularidade seria o principal, pois é a partir dela que se determinaria a reusabilidade e, desta se originariam, posteriormente, as demais propriedades.

No que tange à criação e distribuição, esses OA podem ser produzidos e disponibilizados de muitas maneiras. Porém, há uma espécie de "biblioteca" na 
qual estes recursos podem ser publicados e acessados, são os chamados repositórios. A autora expõe que esses espaços se organizam como as bibliotecas e, antes de armazenar os OA, os catalogam a partir de metadados.

Um dos exemplos de repositório é o BIOE, criado em 2008 e oriundo de uma parceria entre o Ministério da Educação, o Ministério de Ciência e Tecnologia, a Rede Latino-Americana de Portais Educacionais, a Organização dos Estados Ibero-Americanos e outras entidades.

De acordo com as informações disponibilizadas no site da própria entidade,

Esse Banco Internacional tem o propósito de manter e compartilhar recursos educacionais digitais de livre acesso, mais elaborados e em diferentes formatos - como áudio, vídeo, animação, simulação, software educacional - além de imagem, mapa, hipertexto considerados relevantes e adequados à realidade da comunidade educacional local, respeitando-se as diferenças de língua e culturas regionais. (BRASIL, 2017).

Como vemos, o banco disponibiliza objetos educacionais de vários tipos, oriundos de diferentes países e que tratam de temas e conteúdos variados. As buscas podem ser feitas de duas formas: ou por objeto ou por coleção. Na primeira opção, quem está acessando o banco pode escolher o país, o idioma e o tipo de recurso que quer encontrar. Já na segunda opção, pode selecionar os campos de nível de ensino, disciplina, coleção e idioma.

Os OE podem ser publicados por qualquer pessoa desde que o recurso produzido seja aprovado por uma avaliação. No que cerne a este processo, Araújo descreve que é realizado por dois comitês e ocorre da seguinte forma:

O primeiro deles (universidades brasileiras participantes) é composto por professores e alunos da graduação e de pós-graduação de universidades públicas. Essa equipe é responsável pela localização, liberação de uso (direito autoral), avaliação e catalogação dos recursos. O segundo é formado por especialistas do MEC que validam a publicação feita pelo primeiro comitê (ARAÚJO, 2013, p.191).

Em sua publicação, a autora ainda alerta que há apenas um profissional especialista de língua portuguesa (LP) no segundo comitê para avaliar os OA 
desta disciplina. No primeiro, não há nenhum. Ao apurarmos sobre a língua espanhola, verificamos que também há somente um especialista sobre a matéria, mas, diferente da $L P$, ele integra o primeiro comitê e não o segundo, ou seja, é um professor ou aluno da referida disciplina e não um especialista do MEC.

Ao compararmos este número com a quantidade de expertos em física (12), matemática (11) ou biologia (7), por exemplo, que integram os dois comitês, vemos que há uma grande discrepância. Essa disparidade também se reflete na quantidade de recursos disponibilizados pelo banco. Não fizemos a contagem, mas ao realizarmos a busca, a grande maioria dos OA encontrados, para os diferentes níveis de ensino, tinham como foco o ensino de disciplinas da área de exatas, não sendo, portanto, de forma igualitária.

Diante do exposto, tivemos algumas dificuldades para localizar um OE que, do nosso ponto de vista, fosse adequado às propostas que gostaríamos de sugerir. Há vários $\mathrm{OE}$ em língua espanhola, no entanto, grande parte deles são direcionados ao ensino de física, matemática ou biologia. Os que realmente são voltados à aprendizagem de ELE são escassos e, de maneira geral, têm como objetivo o desenvolvimento de conteúdo gramatical ou léxico.

Na seção a seguir, descrevemos as características de dois OA que, ao nosso ver, poderiam ser trabalhados em uma aula de língua espanhola para aprendizes brasileiros e indicamos duas propostas didáticas com o uso desses recursos, ambas dirigidas a alunos do ensino médio.

\section{Análise de AO e propostas didáticas}

Para desenvolvimento de nossa pesquisa, verificamos primeiramente 0 site do BIOE a fim de analisar os OA disponibilizados conforme o nível de ensino e, em seguida, os objetos apresentados para a área de língua estrangeira. A seguir, na figura 1, é possível observar a página inicial do BIOE e os níveis de ensino (Ensino Infantil, Ensino Fundamental, Ensino Médio, 
Educação Profissional, Educação Superior e Modalidades de Ensino) nos quais, ao serem acessados, encontramos as disciplinas correspondentes a cada nível.

Figura 1: Página inicial do Banco Internacional de Objetos Educacionais.

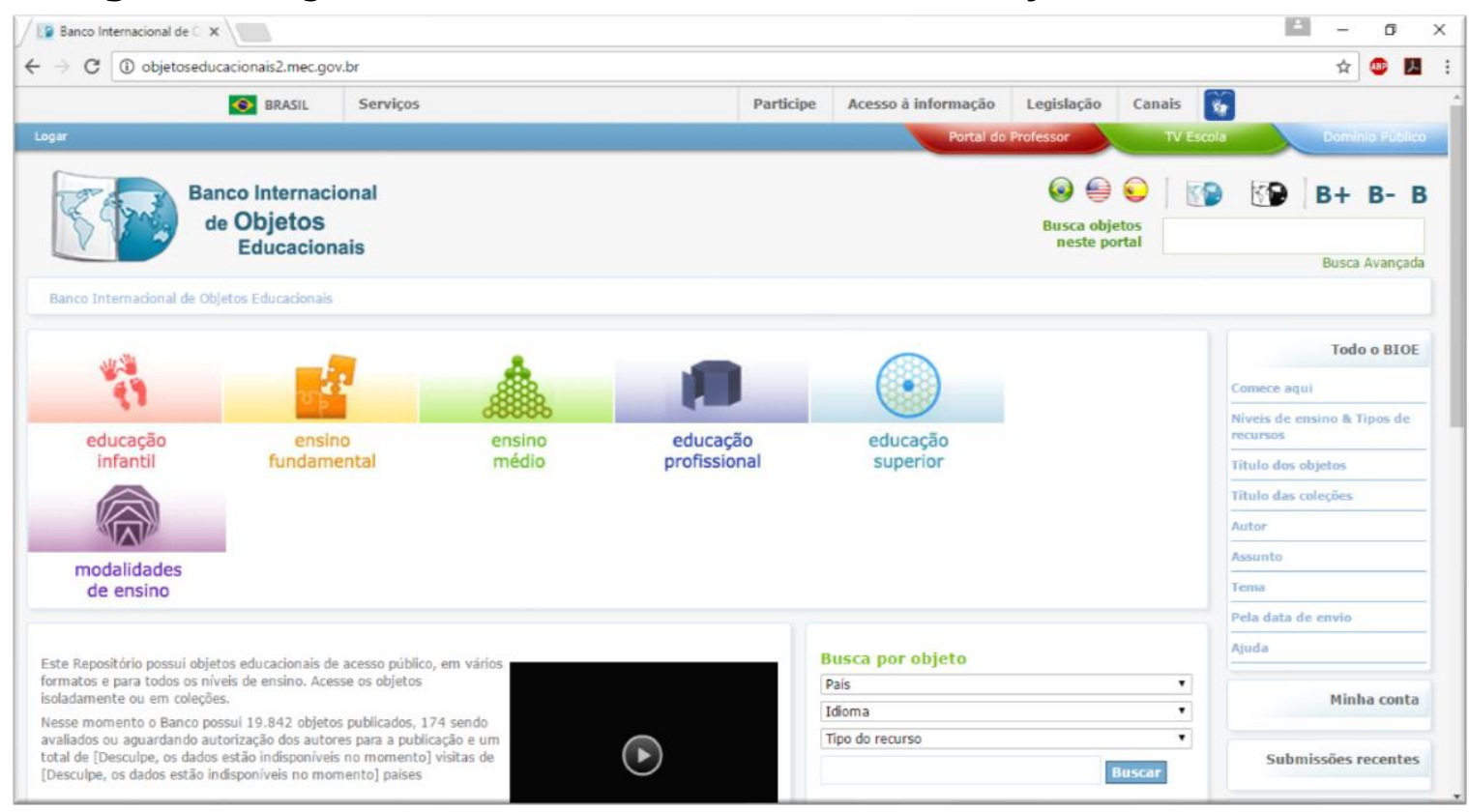

Fonte: <http://objetoseducacionais2.mec.gov.br/>. Acesso em: 04 fev. 2017.

Para o Ensino Médio, contexto das atividades que propomos, os OA estão divididos nas seguintes áreas/disciplinas: Artes, Biologia, Educação Física, Filosofia, Física, Geografia, História, Língua Estrangeira, Língua Portuguesa, Literatura, Matemática, Química e Sociologia. Na seção destinada à Língua Estrangeira, em nossa data de acesso (04 fev. 2017), encontramos 974 OA, sendo 1 (uma) animações/simulações, 917 (novecentos e dezessete) áudios, 1 (um) softwares educacionais e 54 (cinquenta e quatro) vídeos. A seguir, apresentamos as análises dos OA escolhidos e as propostas de atividades, conforme critérios descritos nos tópicos seguintes.

\section{Proposta 1}

Se trabalhar com as TDIC é importante no ensino e aprendizagem de línguas, por que não trabalhar, também, esse conceito com os alunos? A partir 
desse questionamento, propomos uma atividade que evidencie a presença das tecnologias no cotidiano da sociedade, bem como na sala de aula de ELE, com a finalidade de desenvolver a reflexão crítica dos estudantes.

Para tanto, ao depararmos com um Banco que possui novecentos e dezessete áudios, começamos a análise por título com 0 intuito de identificarmos os referentes à língua espanhola, visto que também havia áudios em língua inglesa. Diante disso, objetivamos buscar áudios que atendessem aos seguintes critérios:

- $\quad$ Adequação ao nível dos estudantes (terceiro ano do Ensino Médio) e aos objetivos das atividades sugeridas;

- $\quad$ Aspectos estéticos do OA (nesse caso, o som);

- $\quad$ Conteúdo de ensino presente no OA;

- $\quad$ Tempo de duração, tendo em vista a extensão de uma aula de línguas na escola pública (cerca de $50 \mathrm{~min}$ ).

Como o nosso propósito é desenvolver a oralidade e promover um debate instigando a criticidade dos estudantes em relação ao tema apresentado anteriormente, optamos por trabalhar com o áudio "La tecnología nuestra de cada día: internet" (<http://objetoseducacionais2.mec.gov.br/handle/mec/19944>). O uso de temas diversos presentes em áudios auxiliam o professor a abordar assuntos que podem se tornar temas de redações em processos seletivos para ingresso em universidades, por exemplo, atendendo uma das necessidades dos alunos dos terceiros anos do Ensino Médio.

Considerando o debate reflexivo sobre o uso da tecnologia como foco, apresentamos a seguir um quadro com informações gerais sobre o áudio.

Quadro1: Dados gerais do AO.

- Data de publicação: 08/12/2011;

- Disponível em: <http://objetoseducacionais2.mec.gov.br/handle/mec/19944>;

- Duração: 1 minuto e 21 segundos;

${ }^{4} \mathrm{~A}$ nossa tecnologia de cada dia: internet. (Tradução nossa). 
- Objetivo (segundo o Banco Internacional de OA): conhecer mais um pouco sobre o uso da Internet e desenvolver uma das destrezas da língua: a escuta;

- Descrição do recurso (segundo o Banco Internacional de OA): comenta sobre as facilidades que a Internet traz às nossas vidas como, por exemplo, permite o acesso a informações do mundo todo em pouco tempo.

Fonte: as autoras.

Desse modo, abaixo, segue a transcrição em língua espanhola do áudio utilizado nessa proposta didática:

El uso de internet es una herramienta que ha facilitado algunas facetas de nuestra vida cotidiana. Estar conectadas en la red nos ha permitido acceder a información de todo el mundo, contactarnos con amigos, trabajar colaborativamente y dedicarle tiempo al ocio y la recreación. Podemos bajar música, películas, mandar mensajes a mails y a teléfonos, comprar online, inscribirnos en la facultad. Las páginas que más usamos son: Facebook, Hotmail, Cuevana para bajar películas, RAE (la Real Academia Española), el Google, radios online, Okeyko para mandar mensajes cuando nunca tenemos crédito, You Tube para ver videos y películas, Blog de la facultad, El Guaraní para inscribirnos y Mercado Libre. También, diarios como La Voz, La Nación, Página Doce, todo para estar conectadas. Junto con nosotras conectate al mundo de la Internet, Internet, Internet ${ }^{5}$.

Esse OA por nós escolhido apresenta um som semelhante ao de uma rádio, ou seja, com música ao fundo, por isso, é importante que os aprendizes estejam familiarizados com a língua espanhola para conseguirem entender 0 que ouvem. Assim sendo, cabe ressaltar que não somente o tema pode ser abordado nessa atividade, mas também a variante linguística da Argentina presença de verbo conjugado em "vos" ("conectate al mundo de la Internet") em contraste com outros países de fala hispânica, como o México e a Espanha,

5 O uso da internet é uma ferramenta que tem facilitado algumas facetas da nossa vida cotidiana. Estar conectadas na rede nos permite o acesso à informação do mundo todo, entrar em contato com amigos, trabalhar colaborativamente e dedicar tempo ao lazer e recreação. Podemos baixar música, filmes, mandar mensagens a e-mails e a telefones, comprar online, nos inscrever na faculdade. As páginas que mais usamos são: Facebook, Hotmail, Cuevana para baixar filmes, RAE (a Real Academia Espanhola), o Google, rádios online, Okeyko para mandar mensagens quando nunca temos crédito, You Tube para ver vídeos e filmes, Blog da faculdade, El Guaraní para nos inscrever e Mercado Livre. Também, jornais como La Voz, La Nación, Página Doce, tudo para estar conectadas. Junto conosco conecta ao mundo da Internet, Internet, Internet. (Tradução nossa). 
que usam o verbo conjugado em "tú" ("conéctate"), além do conteúdo "rotina" (dias da semana, atividades cotidianas, tempo livre), por exemplo.

O uso de áudios no ensino de línguas "evoca imágenes que permiten activar contextos y significados relacionados a conocimientos preexistentes en la estructura cognitiva"6 (TALLEI, 2012, p. 168), promovendo a reflexão dos ouvintes com base em sua compreensão oral vinculada ao seu conhecimento prévio.

Na sequencia, apresentamos uma sugestão de atividade com ênfase na oralidade que visa, de modo geral, refletir a respeito das contribuições de ferramentas tecnológicas como a Internet para o processo de ensinoaprendizagem de uma língua estrangeira. Diante disso, ressaltamos que essa atividade deve ser desenvolvida em quatro momentos: introdução ao tema, audição, comentários e debate em grupo, e que o tempo estimado para a realização de cada etapa apresenta-se ao lado de sua indicação. Recordamos, contudo, que a atividade está proposta para uma aula com cerca de 50 minutos de duração.

Quadro2: Passos para proposta da atividade 1.

Introdução ao tema (cerca de $5 \mathrm{~min})$ :

- Para iniciar a atividade, o professor deve mostrar imagens de computadores e algumas redes sociais e, a partir delas, perguntar que relação possuem, de modo a introduzir 0 tema da audição e verificar o conhecimento prévio de seus alunos.

Audição (cerca de 5min):

- Para desenvolvimento da compreensão auditiva, os estudantes escutam uma vez o áudio e, depois, comentam de modo geral o que compreenderam.

- Posteriormente, ouvem mais uma vez para confirmar o que disseram e esclarecer possíveis dúvidas de compreensão oral.

Comentários (cerca de $10 \mathrm{~min}$ ):

- Após a audição, o professor deve perguntar quais páginas da Internet e redes sociais

\footnotetext{
${ }^{6}$ Evoca imagens que permitem ativar contextos e significados relacionados a conhecimentos preexistentes na estrutura cognitiva. (Tradução nossa).
} 
foram mencionadas, anotá-las no quadro para melhor visualização e perguntar, também, quais dessas páginas os alunos conhecem e acessam. Nesse momento, com o objetivo de instigar a reflexão dos estudantes, o professor poderia utilizar de questões tais como:

- Que benefícios temos com o uso de computadores e da Internet?

- O que há na Internet além de redes sociais?

- É possível estudar a língua espanhola com a Internet?

- Em sua opinião, das páginas web mencionadas no áudio, quais podem auxiliar o estudo de um idioma? Por quê?

- Haveria alguma outra página web não mencionada no áudio que poderíamos utilizar para aprender a língua espanhola? Qual?

Debate em grupo (cerca de 15min):

- Depois da realização das três fases descritas acima, com o objetivo de trabalhar a expressão oral em língua espanhola e promover uma reflexão crítica de seus estudantes, o professor teria como alternativa pedir aos alunos que formassem dois grupos para que participem de um debate em sala de aula, sobre o uso da Internet e o ensino de línguas. Um dos grupos apresentaria argumentos que defendam o uso da tecnologia e da Internet para o ensino-aprendizagem de ELE e o outro argumentaria contrariamente. Desse modo, os alunos teriam cinco minutos para juntos organizarem os argumentos e após, debaterem cada um no seu turno.

Fonte: as autoras.

Nessa proposta que apresentamos, devemos nos atentar ao tempo de seu desenvolvimento, pois, dependendo do grupo de alunos e das questões debatidas, a atividade poderia durar a aula toda. Assim sendo, é essencial que o professor seja o mediador do debate e ao final recorde a importância da relação tecnologia e ensino-aprendizagem de língua espanhola, podendo, inclusive, enfatizar conteúdos encontrados no áudio que ouviram como, por exemplo, cultura, variação linguística (verbo conjugado em "vos"- conéctate presente no final do áudio), além de conscientizá-los de que o uso das TDIC pode modificar nosso modo de pensar e contribuir para nossa formação crítica.

É importante ressaltar que este mesmo OA (áudio "La tecnología nuestra de cada día: internet') poderia ser utilizado em atividade semelhante para outro 
público de alunos como, por exemplo, estudantes do curso de graduação em Letras, com Licenciatura em Língua Espanhola, desde que adequado ao seu contexto de estudo. Nesse caso, o debate poderia ser realizado com o grupo todo em um círculo, mas as perguntas propostas os levarão a refletir acerca do questionamento que embasa nosso estudo: "como propor atividades didáticopedagógicas para o ensino de uma língua estrangeira com o uso de tecnologias?". Acreditamos assim, que na formação docente o profissional de língua espanhola pode desenvolver maior conhecimento em relação às ferramentas a serem utilizadas em sua prática e, debatendo com os demais colegas de sala, desenvolver, ainda, uma reflexão conjunta sobre a tecnologia para o exercício de sua profissão.

\section{Proposta 2}

Nesta proposta temos como foco a utilização de um OA disponibilizado pelo Banco Internacional no formato em vídeo e que pode ser acessado no endereço: <http://objetoseducacionais2.mec.gov.br/handle/mec/14287>. Escolhemos este recurso com base nos seguintes critérios:

- Faz parte de uma coleção elaborada pela Secretaria de Educação do Paraná, intitulada como "Habla América", da qual fazem parte vários vídeos sobre alguns países da América Latina, como Bolívia, Peru e Chile;

- Desenvolve conteúdos culturais, léxicos e gramaticais de forma contextualizada;

- Não é um vídeo muito longo, o que pode contribuir para que os alunos não se dispersem ou percam o interesse durante a visualização;

- Apresenta boas características estéticas e técnicas (som e imagem de boa qualidade);

Optamos pelo vídeo, pois acreditamos que, como é algo que possui cenas, linguagens, modelos de comportamento que, muitas vezes, se 
aproximam ao cotidiano do aprendiz, é dinâmico e traz imagens, sons, gestos e movimentos, e seu uso pode ser uma excelente forma de auxiliar, de uma maneira divertida e prazerosa, o processo de construção de conhecimento.

Diante da perspectiva de José Manuel de Moran, em sua obra "O vídeo na sala de aula",

O vídeo deve ser usado em sala principalmente como elemento de sensibilização, para despertar a motivação, a curiosidade e o desejo de pesquisar os temas curriculares; como ilustração, para mostrar 0 que e como se fala, para compor cenários desconhecidos ou para situar os alunos no tempo e no espaço. (MORAN, 1995, p.29)

Desta maneira,

O vídeo pode, assim, proporcionar uma aproximação do aluno à escola. Pode fazer com que ele não sinta um distanciamento tão grande entre a sua realidade cotidiana e o ambiente acadêmico. Pode ser uma estratégia de aproximação tanto do aluno aos conteúdos propostos pelo professor como uma forma também de o discente encontrar sentido no que aprende e ter satisfação em mostrar a seus amigos e familiares aspectos e temas abordados em sala de aula. A partir do momento em que se estabelecem vínculos entre aquilo que o aluno aprende na escola e o que ele vivencia fora dela, contribui-se para o desenvolvimento de sua consciência reflexiva e crítica, o que, por sua vez, vincula-se à sua formação como cidadão. (FERNÁNDEZ; et.al, 2010, p.60-61)

No entanto, há que considerar, conforme já apontado, este tipo de "ferramenta pedagógica", apesar de ser motivadora, não deve ser utilizada sem um planejamento ou ser levada para a sala de aula como um pretexto ou como algo para somente divertir. Assim como toda e qualquer proposta de atividade, com o uso ou não de tecnologia, o uso do vídeo exige uma preparação prévia do professor que pode ser longa. O educador, em um primeiro momento, precisa encontrar o material que atenda aos seus objetivos. Em seguida, deve verificar se este material tem boa qualidade de som e imagem para depois preparar os exercícios que serão propostos antes, durante e depois da projeção. 
Levando em consideração todas as reflexões que foram realizadas até aqui, elaboramos a proposta didática que apresentamos abaixo. Primeiramente, disponibilizamos um quadro com as informações gerais do vídeo utilizado e, posteriormente, os passos para a realização da atividade.

\section{Quadro3: Dados gerais do OA.}

- Data de publicação: 22/07/2009;

- Disponível em: <http://objetoseducacionais2.mec.gov.br/handle/mec/14287>.

- Duração: 09 minutos e 17 segundos;

- Objetivo (segundo o Banco Internacional de OA): aprender a cultura peruana e alguns verbos em espanhol

- Descrição do recurso (segundo o Banco Internacional de OA): mostra a cidade peruana de Cusco e sua história. Ensina o verbo gustar e como usá-lo nas expressões. Aprender as cores.

- Roteiro do vídeo: a gravação pode ser dividida de acordo com eixos temáticos: na primeira parte, podemos dizer que o foco é introduzir alguns dados gerais sobre o Peru e a cidade de Cusco; na segunda seção é desenvolvido o conteúdo do verbo gustar e das expressões que indicam gostos pessoais; em um terceiro momento, por fim, há a abordagem de alguns conteúdos culturais e históricos relacionados ao país, principalmente à cidade de Cusco e à independência peruana, além de ser trabalhado o conteúdo léxico das cores a partir das bandeiras de alguns países latino-americanos.

Fonte: as autoras.

A atividade sugerida tem como objetivo estimular o uso do vídeo como um recurso tecnológico a ser utilizado em aulas de espanhol como língua estrangeira, a partir do qual diversos conteúdos (culturais, gramaticais e lexicais) podem ser abordados. Diante disso, aclaramos que essa proposta pode ser desenvolvida nas etapas apresentadas a seguir:

Quadro 4: Passos para proposta da atividade 2.

Introdução ao tema (cerca de $10 \mathrm{~min}$ ):

- Para iniciar a atividade, o professor deve perguntar aos alunos o que eles sabem a respeito do Peru: dados sobre a geografia, a política, a cultura ou a economia do país, por exemplo. Outra alternativa seria levar imagens que representem de alguma forma aspectos desta região e pedir aos aprendizes que tentem dizer a que elas se referem. 
Visualização do vídeo - parte 01 (entre 10 e 15 min caso o segundo tópico seja solicitado como tarefa; entre 10 e 50 min caso ele seja realizado em sala):

- Como o vídeo trabalha mais de um assunto, optamos por elaborar uma proposta didática que o trabalhe em partes. Desse modo, a princípio, o docente deve sugerir a visualização dos primeiros 3min06s nos quais são abordadas informações sobre a nação peruana e a cidade de Cusco. Para que trabalhem a compreensão auditiva, uma opção seria solicitar aos estudantes que, enquanto assistem à gravação, tentem relacionar os aspectos comentados aos citados por eles mesmos no exercício inicial e que, ao final da visualização, conversem sobre as relações que estabeleceram. Caso seja necessário, o docente pode propor mais uma ou duas visualizações.

- Nessa primeira parte, o vídeo também apresenta a descrição do clima e das paisagens da região, assim como aponta alguns dados históricos, nomes de artistas e de pontos turísticos peruanos (como Templo da Companhia de Jesus; Bairro de San Blás; Machu Picchu; entre outros). Para aprofundar o tema, os alunos podem ser divididos em grupos e incentivados a pesquisar outras informações sobre os tópicos levantados e apresentá-las aos colegas. Esta pesquisa poderia ser solicitada para que fosse realizada em casa (como tarefa) ou na própria escola. Cada grupo seria responsável por um dos tópicos elencados (clima peruano; fauna e flora peruana; grandes artistas; pontos turísticos; etc.) e deveria pesquisar definições, descrições e curiosidades sobre eles. Para mediar esta proposta, o professor pode sugerir que a pesquisa seja feita em determinados sites como, por exemplo, as páginas oficiais de turismo ou de informação do país: Disponível em: <http://www.peru.travel/pt-br/ e http://peru.info/es-pe/>. Acesso em: 21 abr. 2017.

Visualização do vídeo - parte 02 (30 min):

Aqui o professor partiria para a segunda etapa da atividade e de análise do vídeo (de 03min06s até $05 \mathrm{~min} 49 \mathrm{~s}$ ), na qual o conteúdo gramatical do verbo gustar e das expressões sobre gostos são o foco.

- Antes da visualização, o docente deve perguntar aos estudantes quais características peruanas gostaram mais e escrever os comentários no quadro para que já possam se familiarizar com a matéria que irão estudar. Ao fim dessa seção da gravação, uma alternativa seria revisar a conjugação do verbo gustar apresentada pelos personagens e propor a realização de alguns exercícios gramaticais (retirados de alguma gramática ou livro didático ou produzidos pelo próprio docente). Como no vídeo os indivíduos 
descrevem seus gostos como se estivessem participando de uma entrevista, também sugerimos ao docente pedir aos aprendizes que entrevistem os colegas a respeito dos seus gostos pessoais. Assim, praticariam o conteúdo estudado de forma contextualizada e real.

Visualização do vídeo - parte 03 (30 min):

Neste momento, a última parte do recurso seria trabalhada (de 05min49s até 09min $17 \mathrm{~s}$ ). 0 foco é disponibilizar algumas informações sobre aspectos culturais, históricos e políticos de Peru e Cusco (principalmente sobre a independência) e, em seguida, finalizar com a revisão do conteúdo das cores e com a visualização de algumas paisagens peruanas ao som da canção La flor de la Canela, de Chabuca Granda. Esta canção talvez possa ser de difícil compreensão para os alunos já que traz um vocabulário um pouco complexo. Então, sugerimos que, caso julgue necessário ou interessante, o educador leve a letra para que eles possam acompanha-la (indicamos um link para acesso abaixo desse parágrafo) e, em seguida, desenvolva alguma atividade sobre o assunto. "La flor de la Canela" é uma das músicas mais tradicionais e representativas do Peru, então seria relevante se o docente a trabalhasse de forma crítica, propondo, por exemplo, que os alunos tentassem identificar os temas tratados por ela (o limenho, a flor da canela, os lugares por onde ela passa). A seguir, indicamos alguns links que podem auxiliar na elaboração de algo prático, como a apresentação por parte dos alunos de informações sobre a vida e obra da cantora ou da canção analisada:

- Letra da música: Disponível em: <https://www.letras.com/chabuca-granda/592154/>. Acesso em: 06 fev. 2017.

- Reportagens sobre a cantora e a música:

El Comercio: Disponível em: <http://elcomercio.pe/luces/arte/treinta-anos-sin-chabucagranda-historia-flor-canela-cancion-que-hizo-inmortal-noticia-1546709>. Acesso em: 06 fev. 2017.

El País. Disponível em: <http://elpais.com/diario/1983/03/09/cultura/416012405_850215.html>. Acesso em: 06 fev. 2017.

El País. Disponível em: <http://elpais.com/diario/1983/03/09/cultura/416012405_850215.html>. Acesso em: 06 fev. 2017.

- Artigo sobre os cinquenta anos de "La flor de la canela": Disponível em: <http://sisbib.unmsm.edu.pe/BvRevistas/Paediatrica/v04_n1/flor.htm>. Acesso em: 06 fev. 2017. 
Finalização da proposta e produção de um vídeo:

O professor poderia, ao final de toda a proposta, estimular os alunos a gravarem um vídeo no qual filmariam algum lugar da cidade onde vivem e comentariam sobre aspectos culturais, históricos ou políticos do local (como foi feito na gravação que assistiram sobre Cusco). Deste modo, utilizariam o OA que analisaram como modelo e colocariam em prática o uso de um recurso tecnológico para a aprendizagem do idioma, além de praticarem a oralidade. A gravação poderia ter foco o desenvolvimento do gênero textual reportagem, já que, por meio dela, se poderia atender ao objetivo principal da atividade. Para tal gravação, os estudantes teriam que, a princípio, definir seus papéis (câmera, repórter, entrevistados caso haja) e, em seguida, escrever um roteiro da reportagem para que, posteriormente, possam realiza-las. Também poderiam, como no vídeo que assistiram, escolher uma música representativa do local que descreveram e incluí-la à gravação ou discuti-la em sala. As produções poderiam ser divulgadas, por exemplo, em um blog do colégio, nas redes sociais dos alunos ou da instituição e em jornais locais, assim como também poderiam ser socializadas na aula da disciplina.

Fonte: as autoras.

\section{Considerações Finais}

Com base no aporte teórico apresentado, concluímos que o uso de TDIC no processo de ensino e aprendizagem de ELE torna-se cada vez mais essencial tendo em vista o perfil dos alunos (nativos digitais) em nossas salas de aula e suas necessidades diante da sociedade em que vivem.

Como forma de buscar meios para auxiliar docentes e, consequentemente, a formação dos estudantes de língua espanhola, sugerimos atividades didáticas a partir de dois OA (áudio e vídeo) a fim de motivar a oralidade no idioma em questão, bem como sua reflexão em relação aos temas abordados. Desse modo, como já mencionado, os OA dispostos no BIOE estão classificados conforme as disciplinas e nível de ensino, porém, constatamos que podem ser desenvolvidas atividades utilizando os OA para outro nível de ensino além do determinado no Banco Internacional, desde que adaptadas e adequadas aos conteúdos e necessidades correspondentes. 
Entretanto, cabe ressaltar que desconhecíamos a existência do Banco Internacional de Objetos Educacionais e a nomenclatura "objetos de aprendizagem" antes da leitura do estudo de Araújo (2013), ou seja, esta pode ser a realidade de muitos outros profissionais da educação. Dessa forma, defendemos a importância de iniciativas governamentais para divulgação de recursos como esses para capacitação dos docentes em atuação e, inclusive, a socialização desse Banco Internacional em redes sociais, pois acreditamos que muitos não sabem que podem utilizá-lo para buscar recursos ou até mesmo para publicar ferramentas que criam.

Durante nossa busca por objetos de aprendizagem em espanhol no BIOE, percebemos que a maioria deles está voltada ao ensino de matemática ou outras disciplinas da área de exatas. Portanto, defendemos a relevância de novas pesquisas na área de tecnologia no ensino, especialmente no ensino de línguas e voltadas à prática docente, atendendo, também, às necessidades cotidianas dos professores, assim como um maior investimento em programas de formação que capacitem os docentes para uma melhor utilização e um real aproveitamento do potencial didático e educativo dos recursos tecnológicos.

\section{Referências}

ARAÚJO, Nukácia Meyre Silva. A avaliação de objetos de aprendizagem para o ensino de língua portuguesa: análise de aspectos tecnológicos ou didáticopedagógicos? In: ARAÚJO, Júlio; ARAÚJO, Nukácia. EaD em Tela: docência, ensino e ferramentas digitais. Campinas: Pontes, 2013. p.179-207.

BRASIL. Ministério de Educação. Secretaria de Educação a distância. Banco Internacional de Objetos Educacionais. Disponível em:

<http://objetoseducacionais2.mec.gov.br/>. Acesso em: 04 fev. 2017.

FERNÁNDEZ, Gretel Eres (Org.). Publicidade e Propaganda: o vídeo nas aulas de língua estrangeira. São Paulo: Companhia Editora Nacional, 2010.

LÉVY, Pierre. Cibercultura. Tradução de Carlos Irineu da Costa. São Paulo, SP: Editora, 34, 1999. 
MORAN, José Manuel. O vídeo em sala de aula. In: Comunicação \& Educação. São Paulo, ECA-Ed. Moderna, p. 27-35, jan./abr. de 1995. Disponível em: <http://www.eca.usp.br/prof/moran/vidsal.htm>. Acesso em: 24 abr. 2013.

PAIVA, Vera Lúcia Menezes de Oliveira e. O uso da tecnologia no ensino de línguas estrangeiras: breve retrospectiva histórica. In: JESUS, Dánie Marcelo de; MACIEL, Ruberval Franco (Orgs.). Olhares sobre tecnologias digitais. linguagens, ensino, formação e prática docente. Coleção: Novas Perspectivas em Linguística Aplicada. Campinas, SP: Pontes Editores, 2015, v. 44., p. 21-34. Disponível em: <http://www.veramenezes.com/techist.pdf>. Acesso em: 24 jan.2017.

PRENSKY, Marc. Nativos digitais, imigrantes digitais. Tradução de Roberta de Moraes Jesus de Souza. Versão original: Digital Natives Digital Immigrants. On the Horizon, NCB University Press, v. 9, n. 5, 2001, p. 1-6.Disponível em: <https://docs.google.com/document/d/1XXFbstvPZIT6Bibw03JSsMmdDknw jNcTYm7j1aOnoxY/edit>. Acesso em: 23 jan. 2017.

TALLEI, Jorgelina. Dime qué material usas y te diré qué profesor eres. In: BARROS, Cristiano Silva de; COSTA, Elzimar Goettenauer de Marins (Org.). Se hace camino al andar. reflexões em torno do ensino de espanhol na escola. Belo Horizonte: Faculdade de Letras da UFMG, 2012. p. 163-173.

TALLEI, Jorgelina; COELHO, Iandra María Weirich Silva. Formación docente y la aplicación de nuevas tecnologías en la enseñanza de $\mathrm{E} / \mathrm{LE}$ en las escuelas técnicas. In: Texto libre: linguagem e tecnologia, v. 5, n. 2, p. 1-11, 2012. Disponível em: <http://periodicos.letras.ufmg.br/index.php/textolivre>. Acesso em: 26 jan. 2017. 